\title{
A Growing Troubling Triad: Diabetes, Aging, and Falls
}

\author{
Ryan T. Crews, Sai V. Yalla, Adam E. Fleischer, and Stephanie C. Wu \\ Center for Lower Extremity Ambulatory Research (CLEAR), Dr. William M. Scholl College of Podiatric Medicine, \\ Rosalind Franklin University of Medicine and Science, 3333 Green Bay Road, North Chicago, IL 60064, USA \\ Correspondence should be addressed to Ryan T. Crews; ryan.crews@rosalindfranklin.edu
}

Received 5 December 2012; Accepted 11 January 2013

Academic Editor: Neil D. Reeves

Copyright (C) 2013 Ryan T. Crews et al. This is an open access article distributed under the Creative Commons Attribution License, which permits unrestricted use, distribution, and reproduction in any medium, provided the original work is properly cited.

There is a significant and troubling link between diabetes (DM) and falls in the elderly. Individuals with DM are prone to fall for reasons such as decreased sensorimotor function, musculoskeletal/neuromuscular deficits, foot and body pain, pharmacological complications, and specialty (offloading) footwear devices. Additionally, there is some concern that DM patients are prone to have more severe problems with falls than non-DM individuals. Fractures, poorer rehabilitation, and increased number of falls are all concerns. Fortunately, efforts to mitigate falls by DM patients show promise. A number of studies have shown that balance, strength, and gait training may be utilized to successfully reduce fall risk in this population. Furthermore, new technologies such as virtual reality proprioceptive training may be able to provide this reduced risk within a safe training environment.

\section{Introduction}

From 2000 to 2010 the elderly (65+ years) population in the USA has continued its upward trend, increasing by 5.25 million (15\%) to a total of 40.26 million [1]. This amounts to $13 \%$ of the entire population [1]. Thanks to the aging baby boomers population, by the year 2050 the elderly population is expected to reach 88.5 million, which would represent $20 \%$ of the total population [2]. One of the greatest health challenges facing this population is falls. In 2000 there were a reported 10,300 fatal falls by the elderly in the USA that incurred \$179 million in direct medical costs [3]. There were an additional 2.6 million medically treated falls that cost $\$ 19$ billion in medical costs. Other western nations report similar significant burdens with the United Kingdom reporting £981 million (US $\$ 1.9$ billion) in costs for falls in those 60 or more years old in 1999 [4], and in 2001 the annual cost of care attributable to falls in those 65 or older in Australia was $\$ 86.4$ million (US $\$ 66.1$ million) [5]. While the cause of falls is often multifactorial, diabetes mellitus (DM) has been shown to be a significant factor. The significance of the relationship between aging, DM, and falls has been highlighted by previous work that found the annual incidence of falls in elderly individuals with DM to be 39\% [6]. This paper will review the association of fall occurrence and diabetes, the association of fall severity and diabetes, and efforts to limit diabetes associated risks for falls.

\section{Association between Diabetes and Falls}

Falls are a major concern for elderly adults with DM [7]. The high prevalence of falls in ambulatory elderly individuals with DM is well established with reported annual incidence rates of 39\% in those over 65 years [6] and 35\% in those over 55 years [8]. In addition to the reported high incidence of falls in this population, it has been established that DM individuals are at a higher risk for falls $[9,10]$. There are a number of mechanisms by which DM may contribute to falls. Decreased sensorimotor function, musculoskeletal/neuromuscular deficits, foot and body pain, pharmacological complications, and specialty (offloading) footwear devices will be discussed.

\section{Decreased Sensorimotor Function}

Diabetic peripheral neuropathy (DPN) is common among the DM population, and its prevalence increases with age and duration of diabetes [11-13]. While a number of detrimental changes to the nervous system fall under the umbrella of 
DPN, this section will focus on the most common type which is damage to the large nerve fibers that results in decreased sensorimotor function [14]. DPN patients with diminished plantar sensation on their feet have been observed to exhibit increased postural sway along with significant loss of postural control $[15,16]$. Loss of proprioceptive feedback [17] during standing and walking in turn leads to increased risk of falls which is evident from a recent prospective cohort study on 9,249 women aged above 67 years where postural instability and DPN were observed to account for the largest percentage of the relationship between diabetes and falls [18]. Crosssectional studies have also found a strong association between the development of DPN and falls. Among 21 DM patients over 55 years who reported at least one fall in the past year, MacGilchrist et al. found that $86 \%$ had peripheral neuropathy [8]. Furthermore, it has been shown that as DPN severity increases, performance on functional reach tests declines [19]. Thus, as DPN severity increases, there is a higher risk of falls occurring while completing reaching tasks in the standing position. While there are many risk factors that contribute to falls, DPN is definitely a significant contributor [20].

\section{Musculoskeletal/Neuromuscular}

Apart from DPN, lower physical activity, muscle strength, and poor postural control were also found to be among the significant risk factors that influence gait patterns and increased risk of falls among the DM population [21, 22]. Among the elderly population, postural control is an important factor to perform activities such as standing, sitting, walking, and reaching tasks [23-25]. Considering that the feet serve as the base supporting structure during these activities, the strength in lower extremity joints plays a vital role in establishing a strategy for postural stability [26]. Impaired postural control during static balance tests [27] as well as dynamic short whole body anterior translations of 1-4 mm in older patients with DM [28] increases the limitations at the base of support and in turn results in increased risk of falls.

In addition to the lack of sensorimotor function discussed previously, coordination of muscles for postural compensatory strategies is challenged in individuals with DPN. Najafi et al. [17] utilized a novel compensatory index for quantifying postural control strategy to compare strategies utilized by healthy young subjects to strategies of older DPN subjects. In comparison to the healthy young, the older DPN subjects had a significant $10 \%$ reduction in postural compensatory strategy. This was coupled with a $98 \%$ increase in postural sway. This difficulty in postural control coupled with an altered gait pattern [29] further increases the risk of falls in DPN patients.

Low plantar flexion strength has also been observed to be associated with increased center of mass (COM) displacement or sway among DM patients negatively affecting the maximum forward reach distance [24]. Accordingly, while studying ambulatory DM patients, Macgilchrit et al. found that ankle plantar flexion muscle strength was lower among fallers by $40 \%$ compared to nonfallers [8]. Reduced muscle strength has also been shown to result in reduced walking speeds $[25,30]$, and an increased double support phase of the gait cycle. Studies have shown increased double support time to be a significant factor for falls [31-33] especially in people with postural instability [34]. Individuals at high risk for falls likely adopt this increased double support strategy in order to limit the time during which they must maintain balance on a single limb. This further emphasizes the need for exercise training and developing a stable postural control strategy in DM patients to reduce the risk of falls.

\section{Foot and Body Pain/Pharmacological Complications}

While the majority of excess fall risk in patients with diabetes can be attributed to DPN sensorimotor decrements and aberrant neuromuscular control, it is important to recognize that other factors associated with diabetes (e.g., foot and body pain and the use of psychotropic medications and polypharmacy) can also contribute to a heightened fall risk profile.

Foot pain is another recognized risk factor for falls among community-dwelling older adults $[35,36]$. Patients with diabetes frequently experience symptoms of painful polyneuropathy as the distal nerve fibers in the toes and foot begin to deteriorate. Similarly, patients with chronic disabilities encounter greater levels of chronic, generalized body pain $[37,38]$ which also places them at increased risk for recurrent falls [21]. This is because diabetic individuals suffering with chronic pain may be less capable of adhering to productive self-management practices like regular exercise [37] and have poorer mental health and physical functioning [38] which places them at increased risk for falls [35].

Diabetic patients that suffer with neuropathic pain are frequently managed with psychotropic and other central nervous system mediated medications. Amitriptyline and duloxetine hydrochloride, for example, are commonly used to treat the painful symptoms of diabetic neuropathy, the latter being one of only two FDA-approved medications for use in diabetic neuropathy. Psychotropic medications are frequently implicated in falls and nearly double an elderly adult's risk for experiencing a fall $[39,40]$ and having recurrent falls [21, 41]. Older adults suffering with diabetes are also more likely to be taking a greater number of prescription medications [21] and seem to be more sensitive to the effects of polypharmacy than their nondiabetic counterparts [40, 42]. Patients with diabetes start to experience an increased risk of falling with regimens involving just 4 or more prescription medications [42].

One of the hazards of managing diabetes is the increased risk for experiencing unexpectedly low blood glucose levels and symptomatic hypoglycemia. Hypoglycemic episodes can occur with oral hypoglycemic and/or insulin use and frequently result in a state of dizziness, confusion, and postural instability which increases ones' risk for a fall accident [4346]. While the literature has been somewhat mixed regarding the extent to which the level of diabetes control influences fall 
risk $[42,47,48]$, it remains clear that the medications associated with treating DM and its complications can contribute to increased fall risk.

\section{Offloading Footwear}

Footwear such as athletic shoes has been found to reduce fall risk in older adults $[49,50]$. Within the DM population, foot ulcers are highly prevalent $[51,52]$ and often develop due to cumulatively high localized plantar pressure on their feet [53-55]. In order to reduce the risk of ulceration and also for treatment of ulcers, footwear that provides offloading of the localized stress is widely used [55-57]. Even though offloading footwear has not been directly associated with falls, some offloading devices have certainly been found to negatively affect postural stability $[58,59]$. Of most concern are the casts and cast walkers used in the treatment of diabetic foot ulcers. These devices significantly restrict normal gait. In addition to being heavy, prohibiting ankle movement, prohibiting normal heel to toe progressive loading of the foot, and potentially decreasing proprioception, some offloading footwear also creates a limb length discrepancy [60]. Given the association of postural stability to fall risk [61], reduced postural stability due to offloading footwear will increase the risk of falls of those utilizing the footwear. Design modification for offloading footwear such as reduction in strut height and reduced weight has been suggested as a means to improve postural stability [62] which might in turn reduce fall risk.

\section{Association of Fall Severity and Diabetes}

In an editorial concerning complications of diabetes in elderly people, Gregg et al. noted that falls and fractures along with cognitive disorders, physical disability, and other geriatric syndromes may be as great a concern to older people with diabetes as the more traditionally recognized vascular complications [63]. Diabetes increases not only the risk of falls, but also the risk of fractures [64, 65]. Strotmeyer and coworkers found older adults with diabetes to be at higher fracture risk compared with nondiabetic adults with similar bone mineral density [65]. The literature suggests that the fracture risk point estimates described in type 1 diabetes are considerably higher than in type 2 diabetes [66]. However, increased fracture risk in longstanding type 2 diabetes is a paradoxical phenomenon because men and women with type 2 diabetes typically have normal to high bone mineral density [67-69]. Altered body composition and microvascular complications, including retinopathy, peripheral and autonomic neuropathy, hypoglycemia, and use of medications, particularly thiazolidinediones, are all related with increased risk of fractures in older adults with diabetes $[7,70]$.

In addition to a predisposition to fractures with falls, individuals with DM may be prone to poorer rehabilitation. In investigating rehabilitation following hip fracture, Semel et al. [71] found that patients with diabetes had worse outcomes. The authors noted that patients with diabetes had a worse length of stay efficiency (a measure of recovery per each day of hospital stay) compared with other patients. Similarly, when Liberman et al. compared 224 patients with diabetes to 738 patients without diabetes in a prospective cohort study, they found that patients with diabetes had a worse functional outcome following rehabilitation after hip fracture surgery [72]. Ekstrom and colleagues evaluated the health-related quality of life (HRQoL) after hip fractures and noted that patients with diabetes mellitus had more pain, comorbidities, and reduced health status preoperatively than patients without diabetes. The authors further noted that while there were no more medical complications among patients with diabetes during the first postoperative year, cardiac $(P=0.023)$ and renal failures $(P=0.032)$ were more frequent in patients with diabetes at 24 months.

One last factor to consider in the severity of falls is the occurrence of recurrent falls. Pijpers et al. compared the incidence of recurrent falls in older people with and without diabetes with a mean followup of 139 weeks and noted that $30.6 \%$ of the individuals with diabetes and $19.4 \%$ of the individuals without diabetes fell recurrently (incidence rate of 129.7 versus 77.4 per 1,000 persons-years, respectively, HR $=1.67$ (95\% CI: 1.11-2.51)) [21]. The authors noted that the greater number of medication, higher levels of pain, poorer self-perceived health, lower physical activity and grip strength, more limitations in activities of daily living, lowerextremity physical performance, and cognitive impairment may potentially increase the risk of recurrent falls, and these variables together accounted for $47 \%$ of the increased risk of recurrent falls associated with diabetes (adjusted $\mathrm{HR}=1.30$ $(0.79-2.11))$.

\section{Combating DM-Related Fall Risks}

A recent publication regarding falls of elderly people in longterm care facilities found that $49 \%$ of falls in this setting occurred while walking, $24 \%$ while standing, and $21 \%$ while either rising up or lowering oneself [73]. In studying daily physical activity patterns of DPN subjects with a mean age of $59 \pm 8$ years, it was found that each $24 \mathrm{hr}$ day these subjects spend $13.5 \%$ of their time standing and $6.1 \%$ walking and performed 77 sit-to-stand postural transitions per day on average [74]. Therefore, unfortunately there are plenty of opportunities for elderly adults with DM to experience a fall. Accordingly, numerous investigations regarding improving balance, strength, and gait in order to reduce falls have been conducted [27, 30, 75-77].

Weekly balance training sessions with or without additional strength and/or gait training have been shown to reduce fall risk in DM patients [27, 30, 75, 76]. Positive outcomes have been found both in the broad perspective of DM patients in general [76] as well as specifically in DPN patients $[30,75]$. What is more promising is that in a study comparing four groups (DM with fall history $n=7$, DM without fall history $n=9$, non-DM with fall history $n=7$, non-DM without fall history $n=14$ ), the greatest improvements were seen in DM patients with a history of falling [27]. One study to actually track fall occurrence following 
implementation of a strength and balance program for DPN patients did not show a reduction in falls compared to a DPN control group; however, there were several limitations to the study [77]. This was a secondary analysis of a study utilizing subjects with a somewhat low minimum age criteria of 50. Also the majority of the prescribed intervention was to be conducted at home without supervision. Only 8 training sessions were conducted with a physical therapist, all of which occurred during months 1-3. The first balance and strength assessments to occur after initiation of training did not occur until 6 months after study initiation. Finally no information was provided concerning compliance of exercise at home and only $45 \%$ of participants in the intervention group completed "more than half of the required study protocol elements (p. 1572)." In contrast, a study comparing homebased versus "center-based" balance and strength training for 107 community-dwelling adults (DM was not an inclusion criteria) referred for a falls prevention service found that the center-based service demonstrated significantly better results in preventing falls [78].

In addition to traditional balance and strength training, new technologies utilizing virtual reality may provide additional training methods with limited patient risk. It has been previously shown that DM patients either without or with minimum DPN demonstrate reduced toe-obstacle clearance with altered gait patterns during obstacle crossing [79]. In addition to increasing fall risk during daily living, training to improve clearance could be risky in that falls may occur during training sessions requiring subjects to step over obstacles. Recently an investigation validated a virtual reality protocol for assessing obstacle crossing while stepping in place [80]. The study showed that DPN participants had greater difficulty completing the virtual obstacle crossing. It is possible that this paradigm could be used as a minimal risk training program to improve real world obstacle crossing and subsequently reduce fall risk.

\section{Conclusion}

Falls in elderly individuals with DM are a significant burden to the healthcare system. A number of factors tied to DM predispose this population to a higher risk of falls. Additionally, the falls that this population suffers from have the potential to be more severe in terms of injuries sustained as well as the recovery process. Therefore much work is ongoing regarding the reduction of falls in this population. Numerous studies utilizing balance, strength, and/or gait training have demonstrated reduced fall risk for DM patients that undertook the training. More prospective work is needed regarding the long-term outcome of these interventions on actual fall prevention.

\section{References}

[1] C. A. Werner, The Older Population: 2010, in 2010 Census Briefs, United States Census Bureau, 2011.

[2] G. K. Vincent and V. A. Velkoff, THE NEXT FOUR DECADES The Older Population in the United States: 2010 to 2050, in
Population Estimates and Projections, United States Census Bureau, 2010.

[3] J. A. Stevens, P. S. Corso, E. A. Finkelstein, and T. R. Miller, "The costs of fatal and non-fatal falls among older adults," Injury Prevention, vol. 12, no. 5, pp. 290-295, 2006.

[4] P. Scuffham, S. Chaplin, and R. Legood, "Incidence and costs of unintentional falls in older people in the United Kingdom," Journal of Epidemiology and Community Health, vol. 57, no. 9, pp. 740-744, 2003.

[5] D. Hendrie, S. E. Hall, G. Arena, and M. Legge, "Health system costs of falls of older adults in Western Australia," Australian Health Review, vol. 28, no. 3, pp. 363-373, 2004.

[6] L. M. Tilling, K. Darawil, and M. Britton, "Falls as a complication of diabetes mellitus in older people," Journal of Diabetes and Its Complications, vol. 20, no. 3, pp. 158-162, 2006.

[7] K. S. Kim, S. K. Kim, K. M. Sung et al., "Management of type 2 diabetes mellitus in older adults," Diabetes \& Metabolism Journal, vol. 36, no. 5, pp. 336-344, 2012.

[8] C. Macgilchrist, L. Paul, B. M. Ellis, T. E. Howe, B. Kennon, and J. Godwin, "Lower-limb risk factors for falls in people with diabetes mellitus," Diabetic Medicine, vol. 27, no. 2, pp. 162-168, 2010.

[9] P. P. Oliveira, S. Maria Fachin, J. Jozatti et al., "Comparative analysis of risk for falls in patients with and without type 2 diabetes mellitus," Revista da Associação Médica Brasileira, vol. 58, no. 2, pp. 234-239, 2012.

[10] A. V. Schwartz, T. A. Hillier, D. E. Sellmeyer et al., "Older women with diabetes have a higher risk of falls: a prospective study," Diabetes Care, vol. 25, no. 10, pp. 1749-1754, 2002.

[11] K. van Acker, D. Bouhassira, D. de Bacquer et al., "Prevalence and impact on quality of life of peripheral neuropathy with or without neuropathic pain in type 1 and type 2 diabetic patients attending hospital outpatients clinics," Diabetes \& Metabolism, vol. 35, no. 3, pp. 206-213, 2009.

[12] M. J. Young, A. J. M. Boulton, A. F. Macleod, D. R. R. Williams, and P. H. Sonksen, "A multicentre study of the prevalence of diabetic peripheral neuropathy in the United Kingdom hospital clinic population," Diabetologia, vol. 36, no. 2, pp. 150-154, 1993.

[13] S. Tesfaye, L. K. Stevens, J. M. Stephenson et al., "Prevalence of diabetic peripheral neuropathy and its relation to glycaemic control and potential risk factors: the EURODIAB IDDM Complications Study," Diabetologia, vol. 39, no. 11, pp. 13771384, 1996.

[14] S. Tesfaye, "Diabetic Neuropathy," in The Foot in Diabetes, P. R. Cavanagh, A. J. M. Boulton, and G. Rayman, Eds., John Wiley \& Sons, West Sussex, UK, 2006.

[15] B. Najafi, D. Horn, S. Marclay, R. T. Crews, S. Wu, and J. S. Wrobel, "Foot technology, part 1 of 2: assessing postural control and postural control strategy in diabetes patients using innovative and wearable technology," Journal of Diabetes Science and Technology, vol. 4, no. 4, pp. 780-791, 2010.

[16] H. B. Menz, S. R. Lord, R. St George, and R. C. Fitzpatrick, "Walking stability and sensorimotor function in older people with diabetic peripheral neuropathy," Archives of Physical Medicine and Rehabilitation, vol. 85, no. 2, pp. 245-252, 2004.

[17] B. Najafi, D. Horn, S. Marclay, R. T. Crews, S. Wu, and J. S. Wrobel, "Assessing postural control and postural control strategy in diabetes patients using innovative and wearable technology," Journal of Diabetes Science and Technology, vol. 4, no. 4, pp. 780-791, 2010.

[18] A. V. Schwartz, T. A. Hillier, D. E. Sellmeyer et al., "Older women with diabetes have a higher risk of falls: a prospective study," Diabetes Care, vol. 25, no. 10, pp. 1749-1754, 2002. 
[19] S. I. Lin, Y. R. Chen, C. F. Liao, and C. W. Chou, "Association between sensorimotor function and forward reach in patients with diabetes," Gait \& Posture, vol. 32, no. 4, pp. 581-585, 2010.

[20] J. K. Richardson and E. A. Hurvitz, "Peripheral neuropathy: a true risk factor for falls," The Journals of Gerontology A, vol. 50, no. 4, pp. M211-M215, 1995.

[21] E. Pijpers, I. Ferreira, R. T. de Jongh et al., "Older individuals with diabetes have an increased risk of recurrent falls: analysis of potential mediating factors: the Longitudinal Ageing Study Amsterdam," Age Ageing, vol. 41, no. 3, pp. 358-365, 2012.

[22] J. S. Wrobel, R. T. Crews, and J. E. Connolly, "Clinical factors associated with a conservative gait pattern in older male veterans with diabetes," Journal of Foot and Ankle Research, vol. 2, no. 1, article 11, 2009.

[23] M. E. Tinetti, M. Speechley, and S. F. Ginter, "Risk factors for falls among elderly persons living in the community," The New England Journal of Medicine, vol. 319, no. 26, pp. 1701-1707, 1988.

[24] S. I. Lin, Y. R. Chen, C. F. Liao, and C. W. Chou, "Association between sensorimotor function and forward reach in patients with diabetes," Gait \& Posture, vol. 32, no. 4, pp. 581-585, 2010.

[25] P. P. Alvarenga, D. S. Pereira, and D. M. C. Anjos, "Functional mobility and executive function in elderly diabetics and nondiabetics," Revista Brasileira de Fisioterapia, vol. 14, no. 6, pp. 491-496, 2010.

[26] F. B. Horak, "Postural orientation and equilibrium: what do we need to know about neural control of balance to prevent falls?" Age and Ageing, vol. 35, supplement 2, pp. ii7-iill, 2006.

[27] S. Morrison, S. R. Colberg, H. K. Parson et al., "Relation between risk of falling and postural sway complexity in diabetes," Gait Posture, vol. 35, no. 4, pp. 662-668, 2012.

[28] G. D. Fulk, C. J. Robinson, S. Mondal, C. M. Storey, and A. M. Hollister, "The effects of diabetes and/or peripheral neuropathy in detecting short postural perturbations in mature adults," Journal of NeuroEngineering and Rehabilitation, vol. 7, no. 1, article 44, 2010.

[29] J. S. Wrobel and B. Najafi, "Foot technology, part 1 of 2: diabetic foot biomechanics and gait dysfunction," Journal of Diabetes Science and Technology, vol. 4, no. 4, pp. 833-845, 2010.

[30] L. Allet, S. Armand, R. A. de Bie et al., "The gait and balance of patients with diabetes can be improved: a randomised controlled trial," Diabetologia, vol. 53, no. 3, pp. 458-466, 2010.

[31] E. Nordin, R. Moe-Nilssen, A. Ramnemark, and L. LundinOlsson, "Changes in step-width during dual-task walking predicts falls," Gait \& Posture, vol. 32, no. 1, pp. 92-97, 2010.

[32] D. A. Winter, A. E. Patla, J. S. Frank, and S. E. Walt, "Biomechanical walking pattern changes in the fit and healthy elderly," Physical Therapy, vol. 70, no. 6, pp. 340-347, 1990.

[33] S. M. Friedman, B. Munoz, S. K. West, G. S. Rubin, and L. P. Fried, "Falls and fear of falling: which comes first? A longitudinal prediction model suggests strategies for primary and secondary prevention," Journal of the American Geriatrics Society, vol. 50, no. 8, pp. 1329-1335, 2002.

[34] L. Allet, S. Armand, R. A. de Bie et al., "Clinical factors associated with gait alterations in diabetic patients," Diabetic Medicine, vol. 26, no. 10, pp. 1003-1009, 2009.

[35] S. G. Leveille, J. Bean, K. Bandeen-Roche, R. Jones, M. Hochberg, and J. M. Guralnik, "Musculoskeletal pain and risk for falls in older disabled women living in the community," Journal of the American Geriatrics Society, vol. 50, no. 4, pp. 671678, 2002.

[36] A. Gabell, M. A. Simons, and U. S. L. Nayak, "Falls in the healthy elderly: predisposing causes," Ergonomics, vol. 28, no. 7, pp. 965975, 1985.
[37] S. L. Krein, M. Heisler, J. D. Piette, F. Makki, and E. A. Kerr, "The effect of chronic pain on diabetes patients' self-management," Diabetes Care, vol. 28, no. 1, pp. 65-70, 2005.

[38] M. J. Bair, E. J. Brizendine, R. T. Ackermann, C. Shen, K. Kroenke, and D. G. Marrero, "Prevalence of pain and association with quality of life, depression and glycaemic control in patients with diabetes," Diabetic Medicine, vol. 27, no. 5, pp. 578$584,2010$.

[39] R. M. Leipzig, R. G. Cumming, and M. E. Tinetti, "Drugs and falls in older people: a systematic review and meta-analysis: I. Psychotropic drugs," Journal of the American Geriatrics Society, vol. 47, no. 1, pp. 30-39, 1999.

[40] A. J. Campbell, M. J. Borrie, and G. F. Spears, "Risk factors for falls in a community-based prospective study of people 70 years and older," Journals of Gerontology, vol. 44, no. 4, pp. M112M117, 1989.

[41] H. Luukinen, K. Koski, P. Laippala, and S. L. Kivela, "Predictors for recurrent falls among the home-dwelling elderly," Scandinavian Journal of Primary Health Care, vol. 13, no. 4, pp. 294-299, 1995.

[42] E. S. Huang, A. J. Karter, K. K. Danielson, E. M. Warton, and A. T. Ahmed, "The association between the number of prescription medications and incident falls in a multi-ethnic population of adult type- 2 diabetes patients: the diabetes and aging study," Journal of General Internal Medicine, vol. 25, no. 2, pp. 141-146, 2010.

[43] J. M. Nelson, K. Dufraux, and P. F. Cook, "The relationship between glycemic control and falls in older adults," Journal of the American Geriatrics Society, vol. 55, no. 12, pp. 2041-2044, 2007.

[44] S. S. Johnston, C. Conner, M. Aagren et al., "Association between hypoglycaemic events and fall-related fractures in Medicare-covered patients with type 2 diabetes," Diabetes, Obesity and Metabolism, vol. 14, no. 7, pp. 634-643, 2012.

[45] A. V. Schwartz, E. Vittinghoff, D. E. Sellmeyer et al., "Diabetesrelated complications, glycemic control, and falls in older adults," Diabetes Care, vol. 31, no. 3, pp. 391-396, 2008.

[46] J. E. Signorovitch, D. Macaulay, M. Diener et al., "Hypoglycaemia and accident risk in people with type 2 diabetes mellitus treated with non-insulinantidiabetes drugs," Diabetes, Obesity and Metabolism. In press.

[47] D. K. Miller, L.-Y. Lily Lui, F. E. Kaiser et al., "Reported and measured physical functioning in older inner-city diabetic African Americans," The Journals of Gerontology A, vol. 54, no. 5, pp. M230-M236, 1999.

[48] A. V. Schwartz, K. L. Margolis, D. E. Sellmeyer et al., "Intensive glycemic control is not associated with fractures or falls in the ACCORD randomized trial," Diabetes Care, vol. 35, no. 7, pp. 1525-1531, 2012.

[49] H. B. Menz, M. E. Morris, and S. R. Lord, "Footwear characteristics and risk of indoor and outdoor falls in older people," Gerontology, vol. 52, no. 3, pp. 174-180, 2006.

[50] J. L. Kelsey, E. Procter-Gray, U. S. D. T. Nguyenb, W. Li, D. P. Kiel, and M. T. Hannan, "Footwear and falls in the home among older individuals in the MOBILIZE Boston study," Footwear Science, vol. 2, no. 3, pp. 123-129, 2010.

[51] S. Kumar, H. A. Ashe, L. N. Parnell et al., "The prevalence of foot ulceration and its correlates in type 2 diabetic patients: a population-based study," Diabetic Medicine, vol. 11, no. 5, pp. 480-484, 2009.

[52] D. J. Margolis, D. S. Malay, O. J. Hoffstad et al., "Prevalence of diabetes, diabetic foot ulcer, and lower extremity amputation among Medicare beneficiaries, 2006 to 2008: data 
Points \#1," in Data Points Publication Series, Agency for Healthcare Research and Quality, Rockville, Md, USA, 2011, http://www.ncbi.nlm.nih.gov/books/NBK63602/.

[53] A. Veves, H. J. Murray, M. J. Young, and A. J. M. Boulton, "The risk of foot ulceration in diabetic patients with high foot pressure: a prospective study," Diabetologia, vol. 35 , no. 7, pp. 660-663, 1992.

[54] L. A. Lavery, S. A. Vela, D. C. Lavery, and T. L. Quebedeaux, "Reducing dynamic foot pressures in high-risk diabetic subjects with foot ulcerations: a comparison of treatments," Diabetes Care, vol. 19, no. 8, pp. 818-821, 1996.

[55] S. C. Wu, R. T. Crews, and D. G. Armstrong, "The pivotal role of offloading in the management of neuropathic foot ulceration," Current Diabetes Reports, vol. 5, no. 6, pp. 423-429, 2005.

[56] A. J. M. Boulton, "Pressure and the diabetic foot: clinical science and offloading techniques," The American Journal of Surgery, vol. 187, no. 5, supplement 1, pp. S17-S24, 2004.

[57] P. R. Cavanagh, B. A. Lipsky, A. W. Bradbury, and G. Botek, "Treatment for diabetic foot ulcers," The Lancet, vol. 366, no. 9498, pp. 1725-1735, 2005.

[58] R. van Deursen, "Footwear for the neuropathic patient: offloading and stability," Diabetes/Metabolism Research and Reviews, vol. 24, no. supplement 1, pp. S96-S100, 2008.

[59] L. A. Lavery, J. G. Fleishli, T. J. Laughlin, S. A. Vela, D. C. Lavery, and D. G. Armstrong, "Is postural instability exacerbated by offloading devices in high risk diabetics with foot ulcers?" Ostomy Wound Management, vol. 44, no. 1, pp. 26-34, 1998.

[60] M. EI-Nahas, H. M. Gawish, M. M. Tarshoby et al., "Effect of simulated leg length discrepancy on plantar pressure distribution in diabetic patients with neuropathic foot ulceration," Journal of Wound Care, vol. 20, no. 10, pp. 473-477, 2011.

[61] S. R. Lord, P. N. Sambrook, C. Gilbert et al., "Postural stability, falls and fractures in the elderly: results from the Dubbo Osteoporosis Epidemiology Study," The Medical Journal of Australia, vol. 160, no. 11, pp. 684-688, 1994.

[62] R. T. Crews, F. Sayeed, and B. Najafi, "Impact of strut height on offloading capacity of removable cast walkers," Clinical Biomechanics, vol. 27, no. 7, pp. 725-730, 2012.

[63] E. W. Gregg, M. M. Engelgau, and V. Narayan, "Complications of diabetes in elderly people,” British Medical Journal, vol. 325, no. 7370, pp. 916-917, 2002.

[64] W. Ekstrom, A. N. Al-Ani, M. Sääf et al., "Health related quality of life, reoperation rate and function in patients with diabetes mellitus and hip fracture-a 2 year follow-up study," Injury. In press.

[65] E. S. Strotmeyer, J. A. Cauley, A. V. Schwartz et al., "Nontraumatic fracture risk with diabetes mellitus and impaired fasting glucose in older white and black adults: the health, aging, and body composition study," Archives of Internal Medicine, vol. 165, no. 14, pp. 1612-1617, 2005.

[66] J. E. Compston, N. B. Watts, R. Chapurlat et al., "Obesity is not protective against fracture in postmenopausal women: GLOW," The American Journal of Medicine, vol. 124, no. 11, pp. 1043-1050, 2011.

[67] P. L. A. van Daele, R. P. Stolk, H. Burger et al., "Bone density in non-insulin-dependent diabetes mellitus. The Rotterdam Study," Annals of Internal Medicine, vol. 122, no. 6, pp. 409-414, 1995.

[68] V. Rakic, W. A. Davis, S. A. P. Chubb, F. M. A. Islam, R. L. Prince, and T. M. E. Davis, "Bone mineral density and its determinants in diabetes: the Fremantle Diabetes Study," Diabetologia, vol. 49, no. 5, pp. 863-871, 2006.
[69] A. Räkel, O. Sheehy, E. Rahme, and J. LeLorier, "Osteoporosis among patients with type 1 and type 2 diabetes," Diabetes \& Metabolism, vol. 34, no. 3, pp. 193-205, 2008.

[70] A. C. dos Santos, M. Roberto Cucê Nobre, A. Nussbacher et al., "Predictors of the risk of falls among elderly with chronic atrial fibrillation," Clinics, vol. 67, no. 4, pp. 305-311, 2012.

[71] J. Semel, J. M. Gray, H. J. Ahn, H. Nasr, and J. J. Chen, "Predictors of outcome following hip fracture rehabilitation," $P M \& R$, vol. 2, no. 9, pp. 799-805, 2010.

[72] D. Lieberman, M. Friger, and D. Lieberman, "Rehabilitation outcome following hip fracture surgery in elderly diabetics: a prospective cohort study of 224 patients," Disability and Rehabilitation, vol. 29, no. 4, pp. 339-345, 2007.

[73] S. N. Robinovitch, F. Feldman, Y. Yang et al., "Video capture of the circumstances of falls in elderly people residing in long-term care: an observational study," The Lancet, vol. 381, no. 9860, pp. 47-54, 2012.

[74] B. Najafi, R. T. Crews, and J. S. Wrobel, "Importance of time spent standing for those at risk of diabetic foot ulceration," Diabetes Care, vol. 33, no. 11, pp. 2448-2450, 2010.

[75] H. Salsabili, F. Bahrpeyma, B. Forogh et al., "Dynamic stability training improves standing balance control in neuropathic patients with type 2 diabetes," Journal of Rehabilitation Research and Development, vol. 48, no. 7, pp. 775-786, 2011.

[76] S. Morrison, S. R. Colberg, M. Mariano, H. K. Parson, and A. I. Vinik, "Balance training reduces falls risk in older individuals with type 2 diabetes," Diabetes Care, vol. 33, no. 4, pp. 748-750, 2010.

[77] R. L. Kruse, J. W. Lemaster, and R. W. Madsen, "Fall and balance outcomes after an intervention to promote leg strength, balance, and walking in people with diabetic peripheral neuropathy: "feet first" randomized controlled trial," Physical Therapy, vol. 90, no. 11, pp. 1568-1579, 2010.

[78] T. A. Comans, S. G. Brauer, and T. P. Haines, "Randomized trial of domiciliary versus center-based rehabilitation: which is more effective in reducing falls and improving quality of life in older fallers?" Journals of Gerontology A, vol. 65, no. 6, pp. 672-679, 2010.

[79] M. W. Liu, W. C. Hsu, T. W. Lu, H. L. Chen, and H. C. Liu, "Patients with type II diabetes mellitus display reduced toeobstacle clearance with altered gait patterns during obstaclecrossing," Gait \& Posture, vol. 31, no. 1, pp. 93-99, 2010.

[80] G. Grewal, R. Sayeeda, S. Yescheka et al., "Virtualizing the assessment: a novel pragmatic paradigm to evaluate lower extremity joint perception in diabetes," Gerontology, vol. 58, no. 5, pp. 463-471, 2012. 


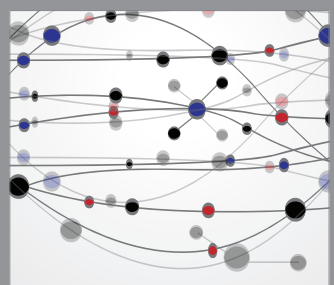

The Scientific World Journal
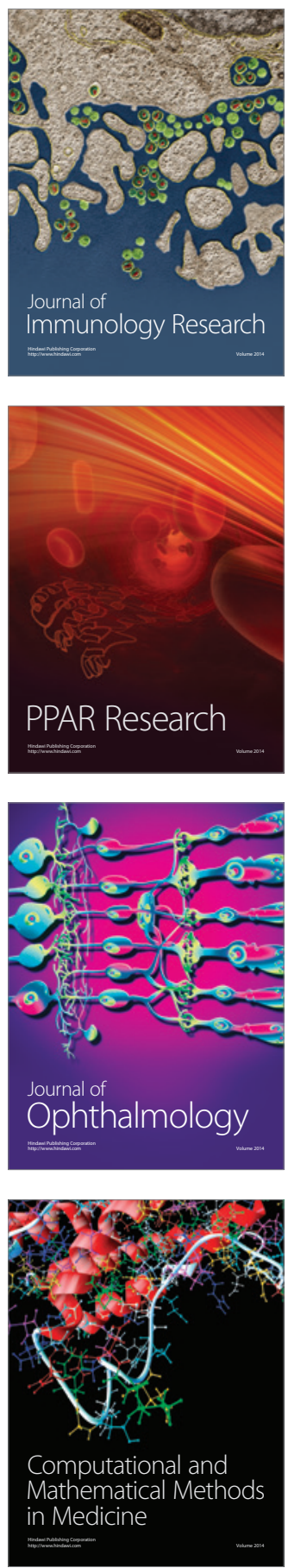

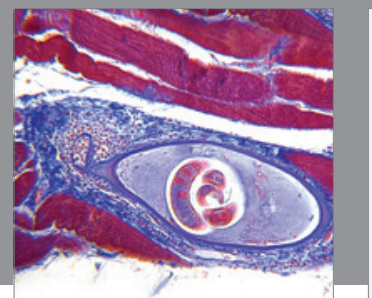

Gastroenterology

Research and Practice
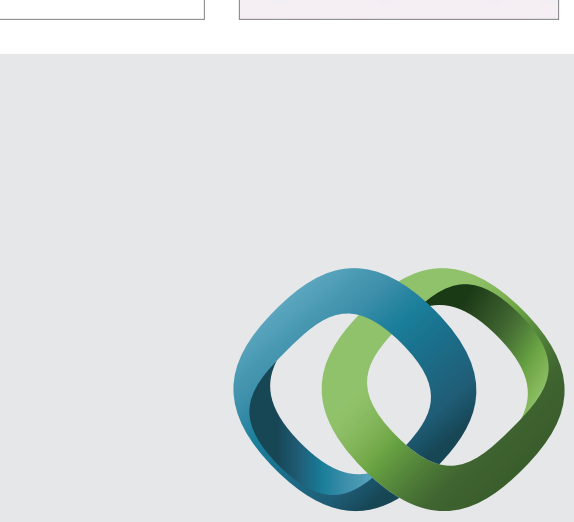

\section{Hindawi}

Submit your manuscripts at

http://www.hindawi.com
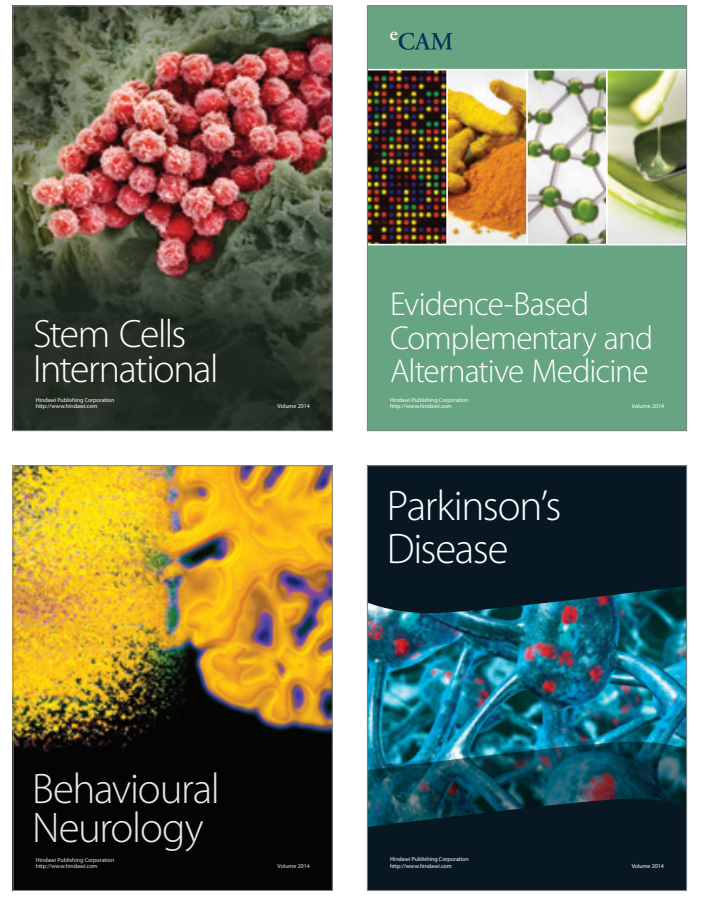
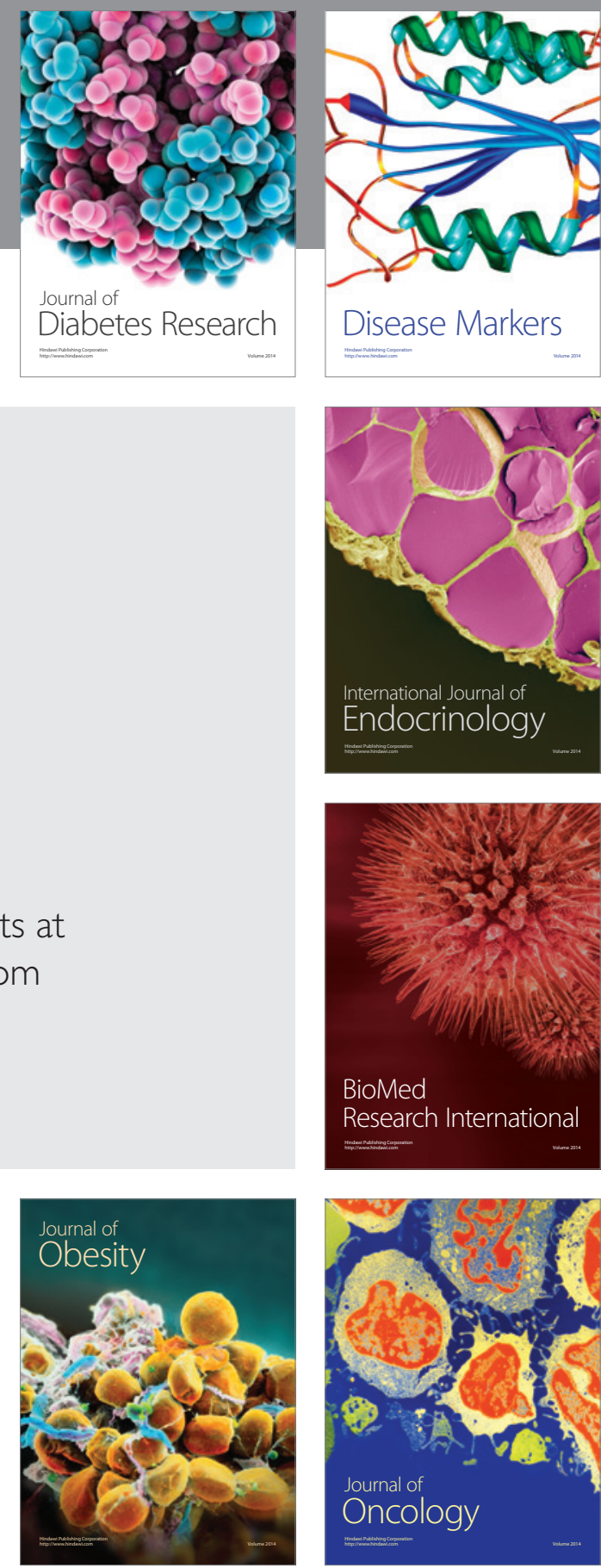

Disease Markers
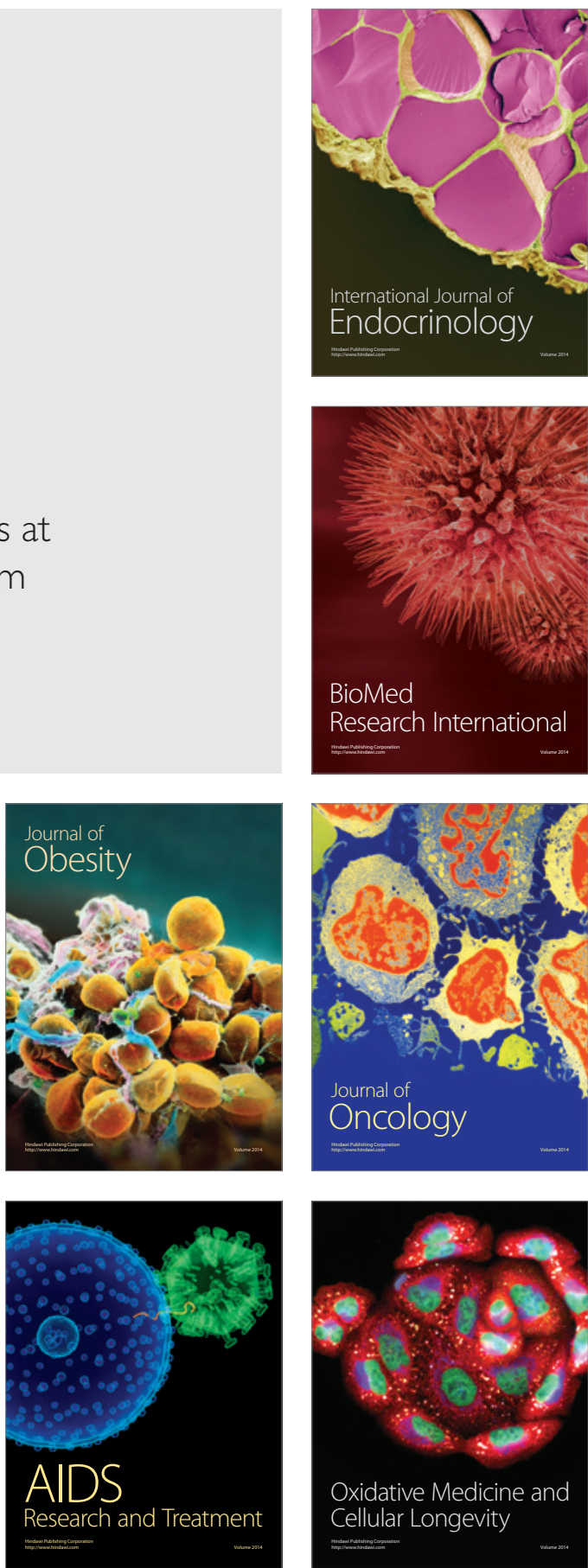